\title{
CORRECTION OF FLUORESCENCE SPECTRA OF ORGANIC COMPOUND SOLUTIONS
}

\author{
V. Kovalevskij \\ Institute of Physics, Savanoriu 231, LT-02300 Vilnius, Lithuania \\ E-mail: vitalij@ar.fi.lt
}

Received 4 May 2006

\begin{abstract}
Fluorescence spectra of various dilute solutions not influenced by the apparatus were obtained using appropriate correction curves. Moreover, the validity of the obtained correction curves is checked by comparing measured fluorescence spectra of standard organic dyes with their spectra reported in various sources. The corrected fluorescence spectra of newly synthesized 3,4,9,10-perylenetetracarboxylic acid derivatives are presented. The observed influence of the changes in the chemical structure of the side groups on their optical spectra is explained by the appearance of the charge transfer state below the first excited singlet state in N,N'-bis(4-diphenylaminophenyl)-3,4,9,10-perylenetetracarboxylic acid diimide (BDFAPhPI) solution, resulting in a huge decrease of the fluorescence efficiency compared to the N,N'-diphenyl-3,4,9,10-perylenetetracarboxylic acid diimide (BPhPI) solution.
\end{abstract}

Keywords: fuorescence spectra correction, perylenetetracarboxylic acid derivatives

PACS: $32.50 .+\mathrm{d}$, 33.20.-t, 33.50.Dq, 39.30.+w

\section{Introduction}

The main information on optical properties of dilute solutions of unknown or newly synthesized chemical compounds might be obtained from steady-state absorption and fluorescence spectra. Together with the steady-state absorption spectra, which provide the basic information on excited level arrangements, fluorescence spectra allow us to investigate vibrational distribution of the ground state, to determine the bandgap energy and position of impurity levels, to investigate charge recombination and energy transfer, as well as peculiarities of aggregation processes [1]. This information is extremely important for the newly synthesized compound characterization dedicated, for example, to the further efficiency and stability improvement of organic light emitting diodes and solar cells. Actually, some derivatives of 3,4,9,10perylenetetracarboxylic acid might be promising materials due to their very good light and chemical stability, high sensitivity to radiation in ultraviolet / visible / near infrared spectral regions. Some optical properties of diluted and concentrated solutions were revealed previously when analysing their absorption spectra [2]. But for the understanding of all optical properties, measurements of their fluorescence spectra are necessary.
Since the fluorescence spectrum of the molecule depends only on its intrinsic properties and, partially, on the environment, the fluorescence spectrum measured with any spectrometer will always differ from this "real" spectrum of the molecule due to the distortion by the registration instrument, which is caused by the detector efficiency and by the monochromator response dependences on the light wavelength. Although the distortion of the measured fluorescence spectra by the instrument is almost unimportant to the quantitative analysis, fully corrected fluorescence emission spectra are necessary for the accurate determination of the fluorescence band shape, for the evaluation of the quantum yields of various compounds, and peculiarities of aggregation and energy transfer processes. Moreover, since the instrument distortion of the spectrum varies when using different luminescence spectrometers, the fully corrected fluorescence spectra are very desirable for the comparison of results recorded by different instruments. The aim of this work is to obtain correction curves for the fluorescence spectrometer, which allows obtaining fluorescence spectra independent of the apparatus and to use these correction curves to correct fluorescence spectra of newly synthesized 3,4,9,10-perylenetetracarboxylic acid derivatives and to understand the influence of the changes in the 
BPhPI

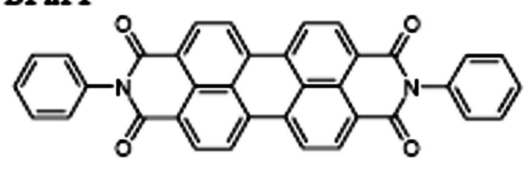

BDFAPhPI

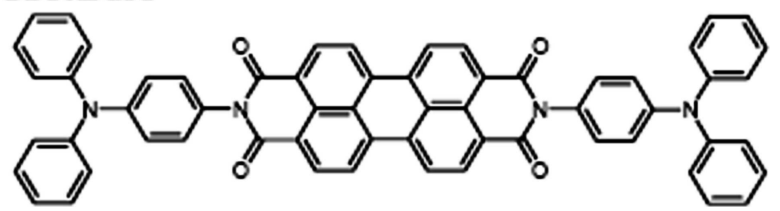

Fig. 1. Chemical structure of N,N'-diphenyl-3,4,9,10-perylenetetracarboxylic acid diimide (BPhPI) and N,N'-bis(4-diphenylaminophenyl)-3,4,9,10-perylenetetracarboxylic acid diimide (BDFAPhPI).

chemical structure of the side groups on their optical spectra.

\section{Materials}

Solvents and reagents were reagent grade, except where noted. The synthesis and purification procedure of 3,4,9,10-perylenetetracarboxylic acid derivatives was described in detail in [3]. Their chemical structure is shown in Fig. 1.

Laser grade dyes Rhodamine B and Sulforhodamine 101 were obtained from the Exciton company and used to prepare corresponding solutions in ethanol. Quinine Sulfate Dihydrate (Fluka AG 22640 Fluorescence Indicator, > 99\%) was dissolved in $0.05 \mathrm{M} \mathrm{H}_{2} \mathrm{SO}_{4}$. The detailed description of the preparation of solvents, the method of the fluorescence spectrum measurement, and other useful information are presented in $[1,4,5]$. All measurements were performed in $1-\mathrm{cm}$ quartz cells. Special attention has been given to the cell cleaning because of the extremely high sensitivity of the fluorescence method to any fluorescent impurity. To avoid obtaining erroneous data, ultrasonic purification in $2.5 \%$ Hellmanex II solution in distilled water with further sonification in ethanol was used for cell cleaning between measurements.

\section{Experimental}

Bulk linear absorption spectra were recorded with a double-beam, double monochromator UV / VIS / NIR Perkin Elmer Lambda 950 spectrometer using the $1 \mathrm{~cm}$ thick quartz cell. Luminescence spectra were collected with a commercially available luminescence spectrometer Perkin Elmer LS50B at room temperature using the standard quartz $1 \mathrm{~cm}$ cell holder in the right-angle excitation geometry. The right-angle excitation geometry for the low optical density solution measurement is the most suitable one since the scattering influence on the fluorescence spectra is minimized when using rightangle excitation geometry compared to transmission or front-face excitation geometries [6].

Actually, it is not a simple procedure to measure the fluorescence correction curve directly. Even after the correction is applied, fluorescence spectra are expected to be accurate only to a few per cent. Therefore, uncorrected fluorescence spectra are often reported, which is quite reasonable for quantitative measurements, but cannot be used for the quantum yield evaluation or for the analysis of the energy transfer process.

One simple approach consists of the determination of the ratio between a synchronously scanned spectrum (the emission and excitation monochromators are simultaneously scanned) for a standard reflector and an energy profile obtained with a good quantum counter [1,5,7].

An alternative relatively simpler method for spectra correction can be obtained by using a correction curve $S(\lambda)$, which is the product of the relative efficiency of the analysing grating monochromator, as a function of the wavelength, and the relative quantum efficiency of the photomultiplier, which is also dependent on the wavelength, provided that both curves are well-known. This correction curve might be obtained by the registration of the emission of the calibrated light source with a well-known intensity distribution $L(\lambda)$. For these purposes a tungsten filament lamp is usually used. Its wavelength distribution might be approximated by that of a blackbody lamp of equivalent colour temperature. The intensity of this lamp $I(\lambda)$ over the whole wavelength interval is measured and then the ratio between this distribution and the well-known spectral output of the lamp is taken $[1,5,7]$ :

$$
S(\lambda)=\frac{I(\lambda)}{L(\lambda)}
$$

This ratio provides a correction curve $S(\lambda)$, which eliminates the influence of wavelength-dependent instrument parameters that affect the observed emission spectra of every sample.

The corrected spectrum is calculated by dividing the measured spectra for the obtained correction curve. For quantum yield measurements, the corrected spectrum in energy units must be multiplied by the wavelength to 
obtain the corrected emission spectrum in photon units $\left(E_{\mathrm{p}}\right)[5,8]$ :

$$
E(\lambda)=\frac{E_{\mathrm{p}}(\lambda)}{\lambda}=\frac{E(v)}{\lambda^{2}}=\frac{E_{\mathrm{p}}(v)}{\lambda^{3}},
$$

where $E(\lambda)$ is the signal for the emission spectrum in energy units per bandpass in wavelength units, $E_{\mathrm{p}}(\lambda)$ is the signal for the emission spectrum in photon units per bandpass in wavelength units, and the other designations are for the emission spectrum in energy or photon units per bandpass in frequency $(\nu)$ units.

\section{Results}

Fluorescence emission spectra were corrected by applying an appropriate correction curve determined for the Perkin Elmer LS50B luminescence spectrometer using a standard black-body lamp as described in Refs. [5,7]. These correction curves were obtained for the wavelength range from 300 to $850 \mathrm{~nm}$ using a standard black-body lamp Bentham CL2, assuming correlated colour temperature to be $3163 \mathrm{~K}$. Firstly, the intensity of the standard lamp versus wavelength $I(\lambda)$ was measured using the detection system consisting of the emission monochromator and the detector of the luminescence spectrometer. Then the "dark counts" were subtracted from the collected data. The "dark counts" measurement is necessary to compensate for the inherent background signal of the photomultiplier tube (PMT). To obtain this value, it is necessary to close the emission monochromator entrance slit for several seconds and to determine the background.

Next, the sensitivity of the detection system $S(\lambda)$ was calculated according to Eq. (1) using the spectral output data $L(\lambda)$ provided with the lamp, converted from the energy units $\left(\mathrm{mW} \cdot \mathrm{m}^{-2} \cdot \mathrm{nm}^{-1}\right)$ to the photon units. This correction curve eliminates the wavelength dependence of the detecting system that distorts the observed emission spectra and provides the corrected emission spectrum in photon units $\left(E_{\mathrm{p}}\right)$. This obtained curve for the fluorescence spectra correction is usually slit-independent for up to $6 \mathrm{~nm}$ wide slits, but sometimes might also be applied for up to $10 \mathrm{~nm}$ wide slits. Unfortunately, this correction curve does not provide correct results for wider slits for the correction of the instrument influence on the measured spectra due to light scattering and polarization peculiarities [9].

Figure 2 shows spectra measured with the Perkin Elmer LS50B luminescence spectrometer and calculated emission spectra of the standard black-body lamp

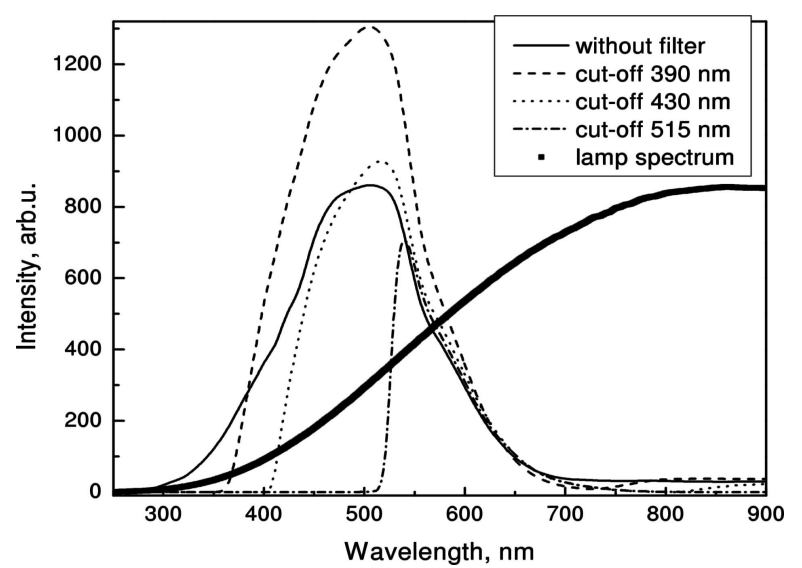

Fig. 2. Theoretical emission spectra of the standard black-body lamp Bentham CL2 assuming correlated colour temperature to be $3163 \mathrm{~K}$ (symbols) and measured with the Perkin Elmer LS50B luminescence spectrometer without any cut-off filter (solid line), with the cut-off filter for $390 \mathrm{~nm}$ (dashed line), with the cut-off filter for $430 \mathrm{~nm}$ (dotted line), and with the cut-off filter for $515 \mathrm{~nm}$ (dashdotted line), respectively.

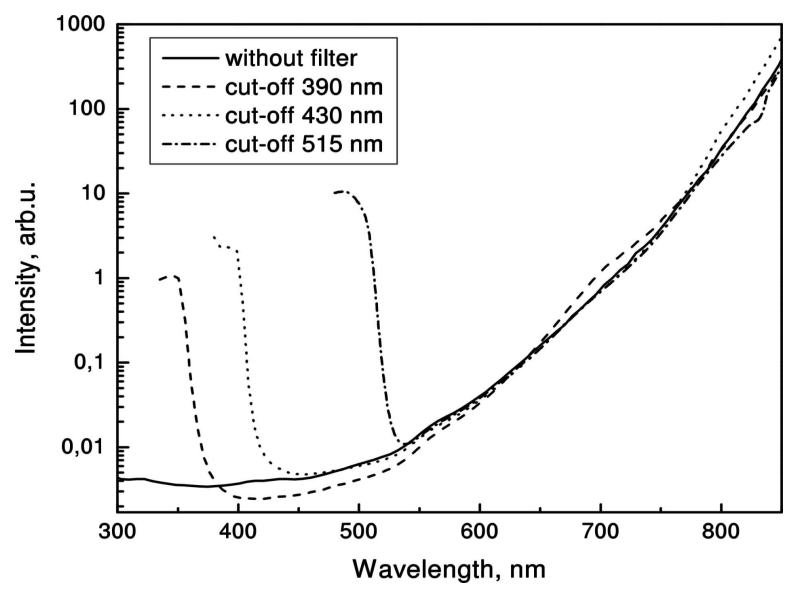

Fig. 3. Fluorescence correction curves for the Perkin Elmer LS50B luminescence spectrometer without any cut-off filter (solid line), with the cut-off filter for $390 \mathrm{~nm}$ (dashed line), with the cut-off filter for $430 \mathrm{~nm}$ (dotted line), and with the cut-off filter for $515 \mathrm{~nm}$ (dash-dotted line), respectively.

Bentham CL2 with estimated correlated colour temperature of $3163 \mathrm{~K}$. Spectra of the lamp emission were measured without any cut-off filter in the emission monochromator part (solid line) and also using several various cut-off filters (cut-off at 390, 430, and $515 \mathrm{~nm}$, respectively). The necessity of the use of various cutoff filters on the emission side is caused by the construction peculiarities of this luminescence spectrometer. It consists only of the single excitation and single emission monochromators, which results not only in the appearance of harmonics of the excitation light at doubled frequencies, but also in considerable enhancement of the influence of the scattered light on the fluorescence spectra. 
The collection of spectra was started from $300 \mathrm{~nm}$ because of the weak intensity of this calibration lamp in the UV region below this wavelength, and was finished at $850 \mathrm{~nm}$ because of the drop in the sensitivity of the photomultiplayer and also because of the drop in the gratings transmission in the NIR region.

Figure 3 represents the corresponding correction curves for the Perkin Elmer LS50B luminescence spectrometer calculated according to Eq. (1) without any cut-off filter in the emission monochromator part (solid line) and using several various cut-off filters (cut-off wavelength at 390, 430, and $515 \mathrm{~nm}$, respectively).

Before applying one of these corrections to the measured spectrum, it is necessary to eliminate the background of the fluorescence, which might originate from the fluorescence and scattering of the sample holder and, perhaps, even of the solution in which the sample is dissolved or suspended. In addition, the system "dark counts", originating from the PMT dark current, should also be compensated before applying general correction curves. An easy way to eliminate these problems is to perform a "blank scan". It has to be performed maintaining the same parameters (i. e., slit width, scanning speed, geometrical position of the cell, excitation wavelength, etc.) as during the measurement of the sample. In case of the diluted solution as a sample, it is better to use the same solvent for such background measurement. It has to be noted that exceptional attention should be given to the cell cleaning because of the extremely high sensitivity of the fluorescence method to any fluorescent impurity. This is especially true if it is necessary to perform many measurements of wellfluorescing dyes. In such case a special treatment of the cell cleaning should be undertaken before a new sample is processed. Otherwise, some erroneous data might be obtained, especially in quantum yield measurements.

After smoothing the "blank" spectrum (if necessary) seeking to improve the signal/noise ratio, it should be subtracted from the measured sample spectrum. This will yield a background-free spectrum, which is free from any fluorescent properties or aberrations related to the sample holder or the solution.

The comparison of background-free fluorescence spectra of Quinine Sulfate in $0.05 \mathrm{M} \mathrm{H}_{2} \mathrm{SO}_{4}$ excited at $346.5 \mathrm{~nm}$, of Rhodamine $\mathrm{B}$ in ethanol after excitation at $415 \mathrm{~nm}$, and Sulforhodamine 101 in ethanol after excitation at $415 \mathrm{~nm}$, measured with the LS50B spectrometer, with the corresponding corrected fluorescence spectra of these materials reported in various sources $[4,5,8,10,11]$ are presented in Fig. 4. Evidently, the obtained correction curves are acceptable

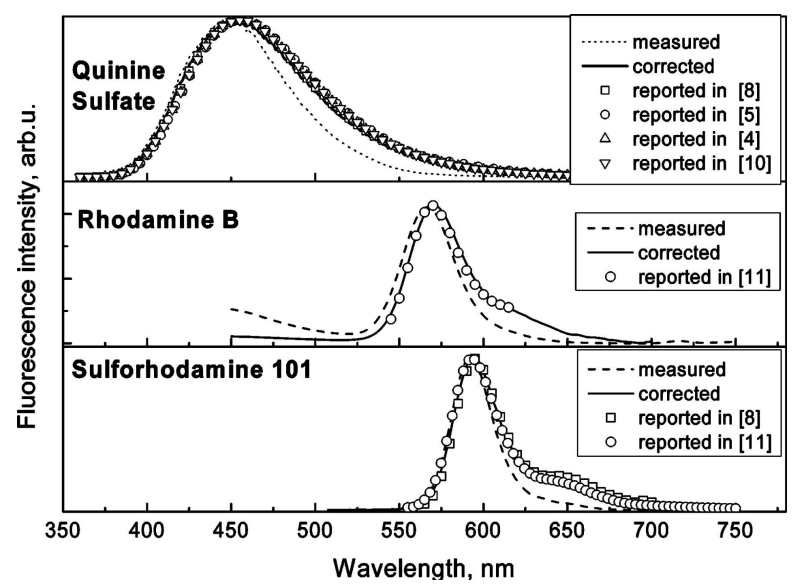

Fig. 4. The comparison of fluorescence spectra: of Quinine Sulfate in $0.05 \mathrm{M} \mathrm{H}_{2} \mathrm{SO}_{4}$ after excitation at $346.5 \mathrm{~nm}$, of Rhodamine B in ethanol after excitation at $415 \mathrm{~nm}$, of Sulforhodamine $101 \mathrm{in}$ ethanol after excitation at $415 \mathrm{~nm}$, measured with the LS50B spectrometer, with the corresponding corrected fluorescence spectra of these materials, reported in $[4,5,8,10,11]$.

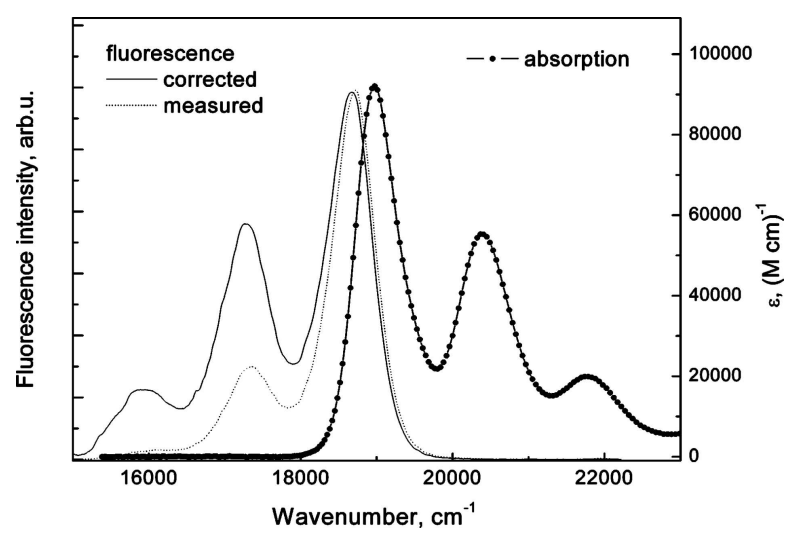

Fig. 5. Measured (dotted line) and corrected (solid line) fluorescence spectra after excitation at $400 \mathrm{~nm}$ as well as the absorption spectrum (symbols) of the dilute $\left(c=1.6 \cdot 10^{-6} \mathrm{M}\right) \mathrm{BPhPI}$ solution in chloroform.

since measured and corrected fluorescence spectra coincide quite well with the corresponding ones, reported in the literature as standard spectra.

Figure 5 shows measured (dotted line) and corrected (solid line) fluorescence spectra after excitation at $400 \mathrm{~nm}$ as well as absorption spectrum (symbols) of the dilute (concentration $c=1.6 \cdot 10^{-6} \mathrm{M}$ ) BPhPI solution in chloroform. All these spectra are plotted on the wavenumber scale instead of the wavelength avoiding "deformation" of the spectrum, which takes place in the case of the wavelength scale. Although wavelengths were converted to wavenumbers just by taking the reciprocal, to convert the intensity on the wavelength scale $I(\lambda)$ to the intensity on the wavenumber scale $I(\nu)$, it has to be multiplied by $\lambda^{2}$ because the bandpass in wavenumbers is not constant when the fluorescence 
spectrum is taken with constant wavelength resolution [5], i.e.,

$$
I(v)=I(\lambda) \lambda^{2}
$$

This multiplication results in the enhancement of the long-wavelength side of the fluorescence spectrum over the red-wavelength side as well as in the shift of the maximum position.

Figure 6 shows the comparison of normalized fluorescence and absorption spectra of BPhPI and BDFAPhPI solutions in chloroform. It should be noted that the fluorescence efficiency of BDFAPhPI solution is almost 200 times weaker compared to the fluorescence of the BPhPI solution.

\section{Discussion}

Obtained correction curves might be suitable in the region of up to $700 \mathrm{~nm}$, since they suddenly increase above this wavelength. As a result, we observed very good coincidence of our corrected spectra with corresponding fluorescence spectra reported in the literature $[4,5,8,10,11]$, enabling us to conclude that the quality of obtained correction curves is acceptable to these measurements (or at least is at the same level of precision, reported by other authors).

Larger difference might be seen only for the redtail of the Sulforhodamine 101 spectra. This is caused by the rapid drop by more than two orders of magnitude both of the detector sensitivity and emission monochromator transmittance above $\sim 750 \mathrm{~nm}$. Therefore, $850 \mathrm{~nm}$ is the reasonable limit to the reasonable measurement of fluorescence spectra of this luminescence spectrometer. The suitability of this instrument for measurements in the $750-850 \mathrm{~nm}$ region should be evaluated with care, especially when subtracting the background, because even a small residual unsubtracted part of the background will cause a huge artificial signal, since it will be multiplied by the correction value hundred times larger compared to its value at $550 \mathrm{~nm}$ (i. e., in the most sensitive spectral region of the LS50B spectrometer) which is close to unity.

Figure 5 shows corrected fluorescence spectra and absorption spectrum (symbols) of the dilute BPhPI solution in chloroform. The absorption spectrum has three distinctive maxima at $21867 \mathrm{~cm}^{-1}, 24107 \mathrm{~cm}^{-1}$, and $26307 \mathrm{~cm}^{-1}$, respectively. They are attributed to the vibronic bands of the first electronic transition. The fluorescence spectrum also possesses a very similar structure with three distinct maxima at 21403, 19203,

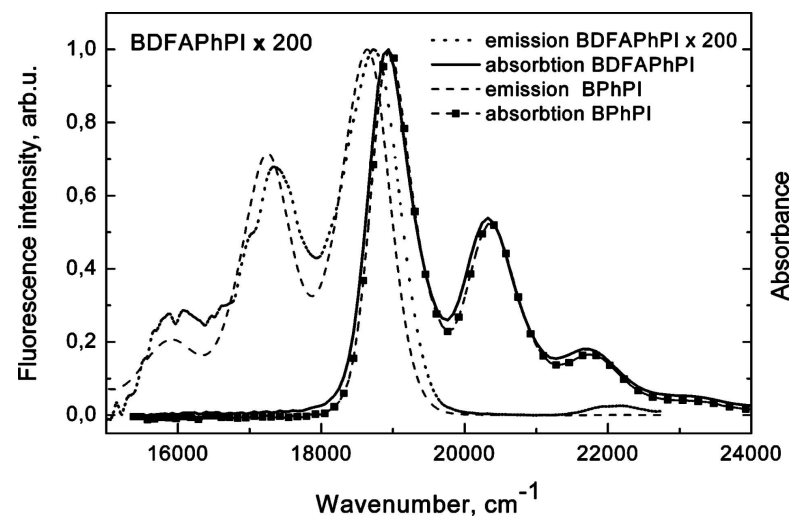

Fig. 6. The comparison of the absorption (squares and dashed line) and fluorescence (dashed line) of BPhPI with corresponding absorption (solid line) and fluorescence (dotted line) spectra of BDFAPhPI solution in chloroform.

and $17084 \mathrm{~cm}^{-1}$, respectively. The Stokes shift is $464 \mathrm{~cm}^{-1}$.

There is a prominent vibrational spacing of about $1400 \mathrm{~cm}^{-1}$ and approximate mirror-image relation between absorption and fluorescence bands, caused by the relatively small differences between the geometries and the solvation of the ground and excited singlet states, which is typical of rigid polycyclic aromatic molecules [12]. Once again, a good agreement with the mirror rule confirms the conclusion that the quality of the obtained correction curve is acceptable.

It should also be noted that BPhPI fluorescence in chloroform is very efficient. Its quantum efficiency might be even close to the efficiency of the Rhodamine $B$ in ethanol, i.e., it might be close to unity.

Figure 6 demonstrates the influence of the changes in the chemical structure on the fluorescence properties of 3,4,9,10-perylenetetracarboxylic acid derivatives. Despite differences in the chemical structure of these pigments, the position and the shape of optical spectra of BPhPI and BDFAPhPI solutions are quantitatively almost the same, i. e., no remarkable shift of the absorption or fluorescence spectra was observed, showing that the main optical transition took place just in the 3,4,9,10-perylenetetracarboxylic acid diimide fragment. But the fluorescence efficiency of BDFAPhPI solution is almost 200 times lower compared to the fluorescence of the BPhPI solution. Unfortunately, because of a very weak signal of the BDFAPhPI solution it is difficult to obtain a high quality fluorescence spectrum, but it might be concluded that in the first approximation the shape and position of the BPhPI and BDFAPhPI fluorescence spectra are very similar, allowing us to state that fluorescence takes place from corresponding lowest excited states. Just in the case of the BDFAPhPI, probably, a lower "dark" level 
exists, efficiently "stealing" excitation from the fluorescent locally excited singlet state. This "dark state" might be attributed to the non-fluorescing "twisted intramolecular charge transfer" (TICT) state $[13,14]$ formation, originated from the charge transfer from the 3,4,9,10-perylenetetracarboxylic acid diimide group to the diphenylaminophenyl group with a subsequent diphenylaminophenyl group twist after excitation. In such case the main part of the fluorescence originates from the untwisted molecular configuration.

\section{Conclusions}

Correction curves for a luminescence spectrometer were obtained under various registration conditions, and their validity was proved by comparing the measured fluorescence spectra of some fluorescence standards with corresponding spectra published in the literature. Corrected fluorescence spectra of new synthesized 3,4,9,10-perylenetetracarboxylic acid derivatives are presented, and the influence of the changes in the chemical structure of the side groups on their optical spectra is revealed. Although the position and the shape of optical spectra of BPhPI and BDFAPhPI solutions in chloroform quantitatively are almost the same, a huge difference in the fluorescence efficiency in these materials is evident. The qualitatively similar shape and position of optical spectra enable us to conclude that fluorescence is taking place from the locally excited singlet state in both molecules, but appearance of the twisted intramolecular charge transfer state below the first excited singlet state in BDFAPhPI effectively quenches fluorescence.

\section{Acknowledgements}

We would like to thank James R. Mattheis from Horiba Jobin Yvon Inc. for useful discussions and Dr V. Sapagovas from Vilnius University for providing 3,4,9,10-perylenetetracarboxylic acid dyes. We are grateful to Prof. Habil Dr S. Juršènas from Vilnius University for providing the black-body lamp Bentham CL2.

\section{References}

[1] C.A. Parker, Photoluminescence of Solutions (Elsevier, Amsterdam, 1968).

[2] V.J. Sapagovas, V. Gaidelis, V. Kovalevskij, and A. Undzenas, 3,4,9,10-Perylenetetracarboxylic acid derivatives and their photophysical properties, Dyes and Pigments 71(3), 178-187 (2006).

[3] V.J. Sapagovas, P. Kadziauskas, A. Undzenas, and R. Purlys, Synthesis and optical properties of 3,4,9,10perylenetetracarboxylic acid derivatives, Environmental Chem. Phys. 23(1), 30-37 (2001).

[4] R.A. Velapoldi and K.D. Mielenz, Standard Reference Materials: A fluorescence standard reference material: Quinine sulfate dihydrate, Natl. Bur. Stand. (U.S.), Spec. Publ. 260-64 (1980).

[5] J. Lakowicz, Principles of Fluorescence Spectroscopy (Kluwer Academic / Plenum Publishers, 1999).

[6] L.F. Vieira Ferreira, S.M.B. Costa, and E.J. Pereira, Fluorescence quantum yield evaluation of strongly absorbing dye solutions as a function of the excitation wavelength, J. Photochem. Photobiol. A 55(3), 361376 (1991).

[7] J.N. Demas and G.A. Crosby, The measurement of photoluminescence quantum yields. A review, J. Phys. Chem. 75(8), 991-1024 (1971).

[8] R.A. Velapoldi and H.H. Tønnesen, Corrected emission spectra and quantum yields for a series of fluorescent compounds in the visible spectral region, J. Fluor. 14(4), 465-472 (2004).

[9] James R. Mattheis from Horiba Jobin Yvon Inc. (private communication).

[10] J.R. Lakowicz, Topics in Fluorescence Spectroscopy (Plenum Press, New York, 1991-1994).

[11] Reference Dye Sampler Kit R14782, Invitrogen Corporation web page probes. invitrogen. com .

[12] J.B. Birks, Photophysics of Aromatic Molecules (Wiley-Interscience, London, 1970).

[13] K. Rotkiewicz, K.H. Grellmann, and Z.R. Grabowski, Reinterpretation of the anomalous fluorescence of $p$-n,n-dimethylamino-benzonitrile, Chem. Phys. Lett. 19(3), 315 (1973).

[14] V. Gulbinas, G. Kodis, S. Jursenas, L. Valkunas, A. Gruodis, J.-C. Mialocq, S. Pommeret, and T. Gustavsson, Charge transfer induced excited state twisting of N,N-dimethylaminobenzylidene-1,3-indandione in solution, J. Phys. Chem. A 103(20), 3969-3980 (1999). 


\title{
ORGANINIU JUNGINIU TIRPALŲ FLUORESCENCIJOS SPEKTRŲ KOREKCIJA
}

\author{
V. Kovalevskij
}

Fizikos institutas, Vilnius, Lietuva

\section{Santrauka}

Buvo išmatuoti ir patikslinti ivairių tirpalu fluorescencijos spektrai, naudojant specialios korekcijos kreives, būdingas mūsu fluorescencijos spektrometrui. Tai būtina padaryti, nes mažos koncentracijos tirpalo fluorescencijos spektras, išmatuotas bet kuriuo spektrometru, skiriasi nuo molekulès fluorescencijos spektro dèl ívairiu iškraipymų, atsirandančių dèl instrumento poveikio. Korekciju kreiviu kokybė ir tinkamumas patikrinti, palyginant žinomų medžiagu išmatuotus ir patikslintus fluorescencijos spekt- rus su literatūroje pateiktais spektrais. Pateikti ịvairių 3,4,9,10perilentetrakarboksirūgšties diimido darinių chloroforme patikslinti fluorescencijos spektrai. Šoninių grupių cheminès sandaros pokyčiu itaka optiniams spektrams aiškinama krūvio pernašos būsenos atsiradimu žemiau pirmos sužadintos singuletinès būsenos N,N'- bis(4-difenilaminofenil)-3,4,9,10 - perilentetrakarboksirūgšties diimido (BDFAPhPI) tirpale, tai lemia drastišką fluorescencijos efektyvumo sumažejimą, lyginant su N,N'-difenil-3,4,9,10perilentetrakarboksirūgšties diimido (BPhPI) tirpalu. 